\title{
Escala (Re)Career - Estilos de Coping: validade de conteúdo
}

\author{
Joana Carneiro Pinto
}

\author{
Universidade Católica Portuguesa, Faculdade de Ciências Humanas. Lisboa, Portugal
}

\begin{abstract}
Resumo: Este artigo apresenta o estudo da validade de conteúdo da Escala (Re)Career: Estilos de Coping, constituída por 36 questões acerca do modo como diferentes pessoas, com 55 anos ou mais, pensam e sentem as transições de carreira. A escala foi avaliada por especialistas reconhecidos em orientação vocacional $(n=6)$ e por um grupo de participantes $(n=4)$ pertencentes ao grupo-alvo a que o instrumento se destina. Avaliou-se a validade de conteúdo da escala, por meio da análise da relevância e clareza dos itens e da relação entre cada item e sua respectiva dimensão. Os resultados indicam qualidades satisfatórias concernentes à relevância (IVC =.991; Kappa $=.488$ ), associação entre item e fator (\% acordo $=95 \%)$ e validade aparente, tendo sido sugeridas melhorias quanto à clareza de alguns itens (IVC =.944; Kappa =.379). Estes resultados justificam o investimento em estudos futuros de validação empírica, nomeadamente através de análises fatoriais.
\end{abstract}

Palavras-chave: estilos de coping, transição, validade do teste, carreiras.

Este artigo tem como principal finalidade realizar um estudo preliminar de uma escala de avaliação de estilos de coping para adultos com 55 anos ou mais em situação de carreira pós-carreira, especificamente por meio de um conjunto de análises focadas na validade de conteúdo.

O conceito de carreira pós-carreira tem sido recentemente utilizado para demarcar uma nova fase de desenvolvimento de carreira que ocorre após a reforma formal de um emprego/trabalho continuado (Pinto, 2021; Pinto \& Rebelo-Pinto, 2019). Na literatura vocacional pouca atenção tem sido dada à fase de transição e adaptação à reforma. Uma análise dos principais modelos desenvolvimentistas da carreira (Bühler, 1964; Erikson, 1959; Greenhaus, Callanan, \& Godschalk, 2010; Havighurst, 1953; Levinson, 1978, 1986; Peck, 1956; Super, 1953, 1980) permite constatar três pontos em comum: (i) a homogeneização indiscriminada de um grupo de pessoas com 65 ou mais anos, que é, na realidade, muito vasto nas suas características, necessidades e vontades; (ii) a apresentação da fase de reforma como "um fim de ciclo" ou "fim de vida", na sequência da desvinculação de um trabalho a tempo inteiro e depois do qual a pessoa vive num "vazio"; e (iii) a indicação da necessidade de uma reavaliação da trajetória de vida passada, ainda que sem qualquer aproveitamento da informação resultante desse processo para a vivência do presente ou eventual projeção no futuro.

Nesse sentido, considera-se que os modelos previamente referidos estão desatualizados ou incompletos, não traduzindo as atuais realidades de carreira das pessoas que vivem em situação de reforma. A constatação dessa situação motivou o desenvolvimento de um novo

* Endereço para correspondência: joanacarneiropinto@ucp.pt subestádio de desenvolvimento de carreira na idade adulta - a carreira pós-carreira. Partindo dos contributos do conjunto de modelos anteriormente mencionados, e que fazem o enquadramento do desenvolvimento do ser humano ao longo do ciclo de vida, a partir de um conjunto de estádios de desenvolvimento e respectivas tarefas desenvolvimentais, propôs-se a concetualização de uma nova fase de vida destinada às pessoas com 65 anos ou mais em situação de reforma.

A carreira pós-carreira requer o envolvimento num conjunto de tarefas desenvolvimentais, relacionadas com o próprio (identidade), com o meio (oportunidade) e com a tomada de decisão e planeamento (adaptação). Essas três dimensões têm inspiração nos modelos recentes de gestão pessoal da carreira (Greenhaus et al., 2010; Pinto, Taveira, \& Ordonez, 2016). A dimensão Identidade agrega um conjunto de tarefas de desenvolvimento vocacional associadas à reconstrução do sentido de identidade, utilidade e autoestima, isto é, um conjunto de passos, estratégias e atividades que as pessoas devem colocar em prática no sentido de explorarem informação sobre si próprias, com foco no passado e na sua relação com o presente. Os modelos teóricos de Bühler (1964), Erikson (1959), Havighurst (1953), Levinson $(1978,1986)$ e Peck (1959) abordam, ainda que de forma muito superficial, a necessidade das pessoas que se encontram nessa fase de vida fazerem um balanço da sua vida e identificarem

\footnotetext{
1 A apresentação e análise crítica de cada um desses modelos teóricos prévios, bem como suas implicações para o desenho deste novo modelo de carreira pós-carreira, nomeadamente em termos de dimensões e tarefas desenvolvimentais, que serviram de inspiração à construção da escala aqui analisada foi efetuada por Pinto (no prelo) num capítulo intitulado "Envelhecimento e carreira: novos contornos", que integra a obra Envelhecimento: uma abordagem multidisciplinar, das editoras RebeloPinto e Pinto, 2021.
} 
uma vasta gama de características pessoais, interesses e valores, de modo a que a perda do papel profissional resultante da reforma não se traduza na perda do sentido de si - da sua identidade, autoestima e utilidade (Pinto, 2021).

A dimensão Oportunidade agrega um conjunto de tarefas de desenvolvimento vocacional associadas à exploração ativa do meio, isto é, um conjunto de passos, estratégias e atividades que as pessoas devem colocar em prática no sentido de explorar proativamente informação sobre atividades, recursos e relações, com foco no presente e na sua relação com o futuro. Os modelos teóricos de Bühler (1964) e Havighurst (1953) são dos poucos que referem, ainda que de forma parca, a necessidade das pessoas identificarem e explorarem uma vasta gama de novas atividades que possibilitem que se mantenham ocupadas durante esse período de vida e, ao mesmo tempo, façam parte de outros grupos de pessoas e se envolvam em compromissos sociais e cívicos.

E, finalmente, a dimensão Adaptação agrega um conjunto de tarefas de associadas ao desenvolvimento de uma atitude otimizada e orientada para esse futuro, isto é, um conjunto de passos, estratégias e atividades que as pessoas devem colocar em prática no sentido do planejamento e da implementação da tomada de decisão, com foco no futuro. Os modelos de Bühler (1964), Greenhaus et al. (2010), Levinson (1978, 1986), Peck (1956) e Super $(1953,1980)$ priorizam maioritariamente a ideia de que a pessoa viva de forma mais calma, afastada da sua atividade profissional principal, apesar de deixarem também alguma margem para a pessoa analisar novas formas de se manter ativa no período de reforma e de deixar um legado para além do seu período vital.

A Tabela 1 apresenta em detalhe a proposta concetual desse novo subestádio de carreira, incluindo as diferentes tarefas desenvolvimentais associadas a cada dimensão.

Tabela 1. Carreira pós-carreira: apresentação de uma proposta de subestádio

\begin{tabular}{|c|c|c|c|c|}
\hline Dimensão & Objetivo & Foco temporal & $\begin{array}{c}\text { Palavra- } \\
\text { chave }\end{array}$ & $\begin{array}{l}\text { Tarefas de desenvolvimento relacionadas } \\
\text { com o próprio }\end{array}$ \\
\hline Identidade & $\begin{array}{l}\text { Reconstruir } \\
\text { o sentido de } \\
\text { identidade, } \\
\text { utilidade e } \\
\text { autoestima }\end{array}$ & Passado - Presente & Autoestima & $\begin{array}{c}- \text { Reavaliar a si próprio. } \\
- \text { Reavaliar sua trajetória/história de vida. } \\
- \text { Reconhecer e explorar novos interesses e competências. } \\
- \text { Reavaliar valores de vida. }\end{array}$ \\
\hline Dimensão & Objetivo & Foco temporal & $\begin{array}{l}\text { Palavra- } \\
\text { chave }\end{array}$ & Tarefas desenvolvimentais relacionadas com o meio \\
\hline Oportunidade & $\begin{array}{l}\text { Explorar, de forma } \\
\text { proativa, atividades, } \\
\text { recursos e relações }\end{array}$ & $\begin{array}{l}\text { Presente - } \\
\text { Futuro }\end{array}$ & Proatividade & $\begin{array}{c}\text { - Analisar expectativas, crenças e mitos sobre } \\
\text { a reforma e analisar atitudes, necessidades e } \\
\text { medos em relação a essa nova fase de vida. } \\
\text { - Identificar e reconhecer recursos. } \\
\text { - Identificar e explorar possibilidades de trabalho } \\
\text { remunerado, de voluntariado e novas atividades de } \\
\text { lazer, e/ou de reingresso no sistema de ensino. } \\
\text { - Desenvolver relações calorosas e afetivas com os outros. }\end{array}$ \\
\hline Dimensão & Objetivo & Foco temporal & $\begin{array}{l}\text { Palavra- } \\
\text { chave }\end{array}$ & $\begin{array}{c}\text { Tarefas desenvolvimentais relacionadas com } \\
\text { o planeamento e a tomada de decisão }\end{array}$ \\
\hline Adaptação & $\begin{array}{l}\text { Desenvolver uma } \\
\text { atitude otimizada } \\
\text { e orientada } \\
\text { para o futuro }\end{array}$ & Futuro & Otimização & $\begin{array}{c}\text { - Definir objetivos e desenvolver planos de ação. } \\
\text { - Monitorizar a implementação do seu plano } \\
\text { de transição e adaptação à reforma. } \\
\text { - Reorganizar/reconfigurar o projeto de vida. } \\
\text { - Avaliar os níveis de resiliência e bem- } \\
\text { estar com essa nova fase de vida. }\end{array}$ \\
\hline
\end{tabular}

Ainda no âmbito dessa proposta de subestádio, antecipou-se que as pessoas possam adotar diferentes estilos de coping, isto é, diferentes atitudes, mais ou menos adaptativas, diante da resolução de cada uma das tarefas desenvolvimentais (Janeiro \& Marques, 2010). Essas diferentes formas de resolução das tarefas deram origem à criação de quatro grupos (estilos de coping) de carreira pós-carreira.
Esses estilos de coping tiveram inspiração, também, num conjunto de outros modelos e autores da literatura vocacional, como é o caso da tipologia de carreira proteana de Hall (2004), da tipologia de carreira sem fronteiras de Arthur e Rousseau (2001), dos perfis de ajustamento à reforma de Schlossberg (2003) e dos estilos de coping com a reforma de De Vries (1979). Assim, o primeiro estilo de coping, que se 
designa por "carreira proativa", engloba todas as pessoas que, diante das diferentes tarefas desenvolvimentais de identidade, oportunidade e adaptação, antecipam e se preparam. Isto é, têm uma atitude proativa e dinâmica de adaptação em novas situações, e de progresso perante novos desafios. O segundo estilo, que se designa por "carreira reativa", engloba todas as pessoas que, mediante as diferentes tarefas desenvolvimentais, não tomam iniciativa de mudança, limitando-se a reagir às circunstâncias de modo improvisado. Podem até ter as competências necessárias para se adaptar à nova fase de vida, mas não tomam iniciativa de mudança. $O$ terceiro estilo, que se designa por "carreira conformada", engloba todas as pessoas que, em diferentes tarefas desenvolvimentais, também não tomam a iniciativa da mudança, mas, em vez de improvisar, como as pessoas do estilo anterior, optam por recusar essas mudanças e dificultam sua própria adaptação com atitudes de resistência, desistência e queixume. O quarto estilo, que se designa por "carreira passiva", engloba todas as pessoas que, em diferentes tarefas desenvolvimentais, simplesmente ignoram ou não se importam, continuando a viver seu dia a dia com mais ou menos limitações, mas sem qualquer consciência da sua nova situação. Salienta-se que as pessoas que se encontram predominantemente em determinado estilo de coping nessa fase da vida não necessariamente resolvem todas as tarefas desenvolvimentais de acordo com o que está definido dentro desse estilo. Além disso, ao longo dos anos de vida subjacentes a essa fase, as pessoas podem oscilar entre os diferentes estilos, adotando posturas de resolução de tarefas mais ou menos adaptativas.

A partir desta proposta de novo subestádio de desenvolvimento de carreira do adulto, foi desenvolvido um instrumento de avaliação - a Escala (Re)Career: Estilos de Coping - que analisa a forma como as pessoas vivenciam a nova fase de vida, isto é, o modo como estão (ou não) capazes de dar uma resposta eficaz ao conjunto antecipado de tarefas desenvolvimentais. $\mathrm{O}$ desenvolvimento desse novo instrumento se prendeu com a necessidade de ultrapassar as visões reducionistas prévias, subjacentes a modelos teóricos e espelhadas em instrumentos de avaliação, que antecipam a transição para a reforma como um fim de ciclo (Wang \& Wanberg, 2017).

$\mathrm{O}$ estudo que aqui se apresenta incide sobre uma análise da validade de conteúdo desse novo instrumento. A validade de conteúdo é um conceito que tem estado sujeito a várias controvérsias e entendimentos quanto a sua definição, apesar de unanimemente reconhecido como fundamental no processo de desenvolvimento de instrumentos de avaliação psicologia (Alexandre \& Colucci, 2011; Polit \& Beck, 2006; Rubio, Berg-Wger, Tebb, Lee, \& Rauch, 2003; Wynd, Schmidt, \& Schaefer, 2003). Assim, por um lado, efetuou-se uma análise do conteúdo da escala, com recurso a juízes peritos na área do construto, que ajuizaram acerca de cada item enquanto representação adequada do fator, das dimensões e das tarefas de desenvolvimento, bem como acerca da relevância e clareza de cada um dos itens da escala. Por outro lado, realizou-se uma análise semântica dos itens, com recurso a participantes da própria população para a qual se construiu o instrumento, que ajuizaram sobre a "validade aparente" da escala/itens.

\section{Método}

\section{Participantes}

Do grupo de juízes, fizeram parte seis participantes, especialistas reconhecidos no domínio da orientação vocacional e desenvolvimento de carreira. Deste grupo, três têm doutorado em Psicologia com especialização em Psicologia Vocacional, um tem doutorado em Psicologia com especialização em Avaliação Psicológica, e dois têm mestrado em Psicologia aplicada à Economia e à Gestão. Todos têm vários anos de experiência profissional na área $(\mathrm{M}=10.17$; $\mathrm{DP}=5.93$; Min-Max = 3-25) e os três dos doutorados também realizam investigação científica acerca da temática das carreiras, estando familiarizados com os procedimentos metodológicos de construção de instrumentos de avaliação. Do grupo da populaçãoalvo, houve quatro participantes, dois do sexo feminino e dois do sexo masculino, com média de idade de 63 . 75 anos (DP $=2.75$; Min-Max $=60-68)$. Destes, três já se encontram reformados $(\mathrm{M}=4.33$ anos; $\mathrm{DP}=2.44$; Min-Max: 1-8anos) e uma participante pensa transitar para a situação de reforma no próximo ano civil.

\section{Instrumento}

(Re)Career-Estilos de Coping é um instrumento de autorrelato desenvolvido por Pinto e Rebelo-Pinto (2020), constituído por 36 questões relativas à vivência da carreira pós-carreira. Concretamente, avalia o modo como diferentes pessoas, em diferentes idades e fases da vida, pensam e sentem as transições de carreira. A escala se destina a adultos com 55 anoa ou mais, que se encontram em situação de preparação ou vivência de uma mudança de carreira, por exemplo, para a reforma. As questões apresentadas derivam das tarefas desenvolvimentais identificadas no enquadramento teórico anteriormente apresentado (Bühler, 1964; Erikson, 1959; Greenhaus, Callanan \& Godschalk, 2010; Havighurst, 1953; Levinson, 1978, 1986; Peck, 1956; Super, 1953, 1980), tendo sido geradas três questões para cada uma das doze tarefas. Para cada questão, apresentam-se quatro alternativas de resposta, que vão ao encontro dos diferentes estilos de coping (carreira proativa, reativa, conformada ou passiva). A tarefa do participante é, para cada questão, selecionar a resposta que melhor corresponde ao modo como pensa ou sente sua atual situação de (transição para a) reforma. No final do preenchimento do instrumento, conta-se a frequência com que as respostas pertencentes a cada estilo de coping foram selecionadas. $\mathrm{O}$ estilo de coping com maior pontuação (maior frequência absoluta) será o que melhor descreve a atitude do adulto diante da situação de (transição para a) reforma. 


\section{Procedimento}

Os juízes especialistas receberam um convite à participação nesta investigação por telefone, tendo-se posteriormente enviado por e-mail uma carta explicativa da relevância dos conceitos envolvidos e do instrumento, bem como um exemplar da escala desenvolvido especificamente para efeitos desta investigação. Concretamente, cada juiz, individualmente, obteve acesso às 36 questões da escala, que foram apresentadas com ordem aleatória. Ao mesmo tempo, foi disponibilizada uma tabela onde constavam as três dimensões e as doze tarefas desenvolvimentais anteriormente apresentadas. Não foi mencionado quantas questões existiam na escala para cada tarefa.

Aos juízes foram propostas três tarefas: (i) estabelecer uma associação entre cada questão da escala e sua respectiva dimensão, e, dentro destas, sua respectiva tarefa de desenvolvimento, com a finalidade de verificar seu grau de concordância na associação entre item e fator; (ii) avaliar a relevância de cada um dos itens para a avaliação do construto em causa, a partir de uma escala Likert de 4 pontos ( 1 = não relevante; 2 = necessita de grande revisão para ser relevante; 3 = necessita de pequena revisão para ser relevante; 4 = relevante) (Alexandre \& Colucci, 2011); e (iii) avaliar a clareza de cada um dos itens para a avaliação do construto em causa, a partir de uma escala Likert de 4 pontos $(1$ = não claro, 2 = pouco claro, $3=$ bastante claro, $4=$ muito claro) (Alexandre \& Colucci, 2011).

Consideraram-se as seguintes características, de forma a assegurar que estes juízes independentes produziam conclusões semelhantes: (i) conhecimento da hipótese de investigação (conceito de carreira pós-carreira, estilos de coping na transição e adaptação à reforma) (Bakeman \& Gotman, 1986 citados em Almeida \& Freire, 2003); (ii) tarefas desenvolvimentais bem definidas, exaustivas e mutuamente exclusivas (Almeida \& Freire, 2003); e (iii) independência e não contacto entre observadores (Kripendorff, 1980 citado em Almeida \& Freire, 2003).

Considerou-se que a percentagem de concordância entre os juízes deveria ser igual ou superior a $80 \%$, de acordo com a seguinte fórmula: $\% \mathrm{~A}=[\mathrm{Na} /(\mathrm{Na}+\mathrm{Nd})] \times 100^{2}$ (Almeida\& Freire, 2003; Pasquali, 2011) para a manutenção do item na escala. Considerou-se igualmente que o índice de validade de conteúdo (IVC) - ou seja, a proporção de itens que recebe pontuação de 3 ou 4 pelos juízes no que concerne à relevância e clareza para avaliação do construto - deveria alcançar um valor de concordância mínima de 0.80 para cada item, de acordo com a seguinte fórmula: IVC = número de respostas " 3 " ou "4"/número total de respostas (Alexandre \& Colucci, 2011). Foi também calculado o IVC da relevância e da clareza para o instrumento como um todo a partir da média dos valores dos itens calculados separadamente, ou seja, o $\sum$ IVC de cada

2 Na: número de unidades verificadas simultaneamente por todos os juízes; Nd: número de unidades verificadas apenas por alguns dos juízes. item/número de itens da escala (Polit \& Beck, 2006). O coeficente de kappa ( $\mathrm{k}$ ) de Conger, isto é, a proporção de acordo entre os avaliadores após ser retirada a proporção esperada de acordo devido ao acaso, foi também calculado, para a relevância e clareza da escala, por meio da seguinte expressão: $\mathrm{K}=(\mathrm{Pa}-\mathrm{Pe}) /(1-\mathrm{Pe})^{3}$, tendo sido usados como interpretações dos valores de Kappa os sugeridos por Landis e Koch (1977).

Os participantes (futuros destinatários da prova) receberam um convite à participação nesta investigação por e-mail e uma carta explicativa da relevância dos conceitos envolvidos e do instrumento, bem como um exemplar da escala desenvolvido especificamente para efeitos desta investigação. A tarefa que lhes foi proposta consistiu na aplicação individual da escala e no registo de todas suas verbalizações. Este método, designado por reflexão falada - thinking aloud (Goldman, 1971 citado em Almeida \& Freira, 2003; Pasquali, 2011), consistiu em solicitar aos participantes que, enquanto preenchiam a escala, verbalizassem um conjunto de informações relativas às suas impressões em relação a cada questão, para analisar a forma como cada questão é abordada e realizada, os processos utilizados e as facilidades ou dificuldades encontradas. Mais concretamente, procurou-se apreciar: o conhecimento das atitudes gerais dos participantes diante dos itens, a eficácia e qualidade das várias alternativas de resposta formuladas, as ambiguidades associadas ao formato/conteúdo dos itens, processos (cognitivos) e estratégias usadas nas suas respostas, itens mal construídos, dificuldades sentidas na escala em alguns itens, (in)suficiência das instruções e estimativa do tempo requerido para a realização da escala.

\section{Resultados}

\section{Análise do grupo de juízes}

Na Tabela 2, apresentam-se os resultados da avaliação do grupo de juízes a cada uma das questões (itens) da escala $\mathrm{Re}$ (Career). Especificamente, indicam-se as questões e suas respectivas dimensões e tarefas de desenvolvimento, assim como as percentagens de acordo dos juízes em relação a essa organização. Entre os 36 itens apresentados, verifica-se 100\% de acordo dos juízes num total de 26. Em dez itens, encontram-se discrepâncias na sua posição. Destes itens, quatro situam-se na dimensão "Identidade", um na dimensão "Oportunidade" e os cinco restantes na dimensão "Adaptação". Importa ainda salientar que, de dez itens, cinco geraram desacordo no que diz respeito à dimensão de pertença (itens $2,3,32,33$ e 35), e nos cinco restantes (itens $8,9,21,27,30$ ), os juízes estavam de acordo quanto à dimensão, mas não quanto à tarefa de desenvolvimento. A título de exemplo, os itens 2 e 3

3 As fórmulas de cálculo de $\mathrm{Pa}$ (proporção de concordância) e Pe (proporção esperada de acordo devido ao acaso) são: $P_{a}=\frac{1}{n} \sum_{i=1}^{n} \sum_{k=1}^{q} \frac{r_{i k}\left(r_{i k}-1\right)}{r_{i}\left(r_{i}-1\right)} P_{e}=\sum_{k=1}^{q} \bar{p}^{2}+_{k}-\sum_{k=1}^{q} s_{k}^{2} / r \quad \bar{p}+_{k}=\frac{1}{r} \sum_{g=1}^{r} p_{g k} \quad s_{k}^{2}=\frac{1}{r-1} \sum_{g=1}^{r}\left(p_{g k}-\bar{p}+_{k}\right)^{2}$ 
pertencem originalmente à dimensão "Identidade", mas um dos juízes considerou que poderiam pertencer à dimensão "Oportunidade". Também os itens 32, 33 e 35 pertencem originalmente à dimensão "Adaptação" mas alguns dos juízes consideraram que poderiam pertencer à dimensão "Oportunidade". Os itens 8 e 9 pertencem à dimensão "Identidade" e estão atribuídos à tarefa de desenvolvimento "reconhecer e explorar novos interesses e competências", mas foram ambos considerados como associados à tarefa "reavaliar a si próprio". O item 21 pertence à dimensão "Oportunidade" e está atribuído à tarefa "Identificar e explorar possibilidades de trabalho remunerado, de voluntariado e novas atividades de lazer, e/ou de reingresso no sistema de ensino", mas foi considerado como associado à tarefa "Identificar e reconhecer recursos". E os itens 27 e 30 pertencem à dimensão "Adaptação" e estão atribuídos à tarefa de desenvolvimento "Definir objetivos e desenvolver planos de ação" e "Monitorizar a implementação do seu plano de transição e adaptação à reforma", respectivamente, mas foram considerados como associados à tarefa "Reorganizar/reconfigurar o projeto de vida" e "Promover os níveis resiliência, de bem-estar e satisfação com esta nova fase de vida".

Tabela 2. Percentagens de acordo dos juízes na associação entre item e sua respectiva dimensão $(\mathrm{n}=6)$

$\begin{array}{lccc}\text { Questão } & \text { Dimensão } & \text { Tarefa de desenvolvimento } & \% \text { de } \\ \text { Acordo }\end{array}$

\section{Como me vejo a mim próprio/a,} como pessoa, nesta fase de vida?

2. Como me vejo a mim próprio/a nesta fase da vida, em termos de saúde física?

3. Como me vejo a mim próprio/a nesta fase da vida, em termos de saúde mental?

\section{Como vejo a história da minha vida?}

\section{Como me sinto ao pensar no meu passado?}

6. Como relaciono meu passado com meu futuro?

7. Tenho consciência dos meus gostos e interesses?

8. Tenho consciência daquilo que sou capaz de fazer?

9. Tenho consciência dos meus pontos fortes?

10. Sei o que é importante para mim como pessoa?

11. Sei o que é importante para mim como membro de uma família?

12. Sei o que é importante para mim como cidadão/ã?

13. Que ideias tenho sobre esta fase de vida?

14. Que expectativas tenho para esta fase de vida?
Identidade

- Reavaliar-se a si próprio

Identidade $\quad-$ Reavaliar-se a si próprio

Identidade

- Reavaliar-se a si próprio

Identidade

- Reavaliar a sua trajetória/história de vida

100

Identidade

Identidade

- Reavaliar a sua trajetória/história de vida

- Reavaliar a sua trajetória/ história de vida

Identidade

- Reconhecer e explorar novos interesses e competências

- Reconhecer e explorar novos interesses e competências

- Reconhecer e explorar novos interesses e competências

- Reavaliar valores de vida

- Reavaliar valores de vida

- Reavaliar valores de vida

- Analisar expectativas, crenças, e mitos sobre a reforma e analisar atitudes, necessidades e medos em relação a esta nova fase de vida

- Analisar expectativas, crenças, e mitos sobre a reforma e analisar atitudes, necessidades e medos em relação a esta nova fase de vida 


\section{Que receios tenho sobre esta fase de vida?}

16. Sei que apoios sociais posso ter nesta fase da vida? Oportunidade

\section{Sei que apoios familiares posso ter nesta fase da vida?}

18. Sei como ativar os meus apoios nesta fase da vida?

19. Que oportunidades de lazer e/ou voluntariado já explorei para esta fase da vida?

20. Que oportunidades de formação, e/ou trabalho já explorei para esta fase da vida?

21. Que oportunidades familiares já explorei para esta fase da vida?

\section{Como me sinto com as outras pessoas?}

23. Como me relaciono com as outras pessoas?

24. Gosto de cultivar amizades e procurar novos amigos?

\section{Tenho objetivos para o futuro?}

\section{Tenho planos para o futuro?}

27. Se não conseguir concretizar os meus planos, que alternativas tenho?

\section{O que estou fazendo para concretizar} meus planos para esta fase de vida?

\section{O que estou a fazer para conseguir o que quero nesta fase da vida?}

\section{Como reajo face aos obstáculos?}

\section{Tenho consciência das mudanças} que a reforma traz?
Oportunidade

- Analisar expectativas, crenças, e mitos sobre a reforma e analisar atitudes, necessidades e medos em relação a esta nova fase de vida

- Identificar e reconhecer recursos 100

Oportunidade

- Identificar e reconhecer recursos

- Identificar e reconhecer recursos

- Identificar e explorar possibilidades de

Oportunidade trabalho remunerado, de voluntariado e novas atividades de lazer e/ou de reingresso no sistema de ensino

- Identificar e explorar possibilidades de

Oportunidade trabalho remunerado, de voluntariado e novas atividades de lazer, e/ou de reingresso no sistema de ensino

- Identificar e explorar possibilidades de

Oportunidade trabalho remunerado, de voluntariado e novas atividades de lazer, e/ou de reingresso no sistema de ensino

Oportunidade

- Desenvolver relações calorosas e afetivas com os outros

- Desenvolver relações calorosas e afetivas com os outros

- Desenvolver relações calorosas e afetivas com os outros

- Definir objetivos e desenvolver planos de ação

- Definir objetivos e desenvolver planos de ação

- Definir objetivos e desenvolver planos de ação

- Monitorizar a implementação do seu

Adaptação plano de transição e adaptação à reforma

- Monitorizar a implementação do seu

Adaptação plano de transição e adaptação à reforma

- Monitorizar a implementação do seu

Adaptação plano de transição e adaptação à reforma

Adaptação - Reorganizar/reconfigurar o projeto de vida 
32. Tenho consciência do impacto da reforma no meu estilo de vida?

33. Tenho consciência do impacto da reforma na organização do meu dia a dia?

\section{Como encaro a reforma?}

35. Como me sinto em relação à reforma?

36. Como avalio ou antecipo neste momento o meu grau de satisfação em relação à reforma?
Adaptação - Reorganizar/reconfigurar o projeto de vida $\quad 66.7 \%$

Adaptação - Reorganizar/reconfigurar o projeto de vida $\quad 80 \%$

Adaptação - Promover os níveis resiliência, de bemestar e satisfação com esta nova fase de vida

Adaptação

- Promover os níveis resiliência, de bemestar e satisfação com esta nova fase de vida

Adaptação - Promover os níveis resiliência, de bemestar e satisfação com esta nova fase de vida

Resultado Médio:

$95.23 \%$
Na Tabela 3 apresentam-se os índices de validade de conteúdo tendo em conta a relevância e a clareza de cada um dos itens, calculados a partir da avaliação dos juízes acerca de cada um dos itens para o construto em causa. No que diz respeito ao IVC para a relevância dos itens, constata-se que, dos 36 itens da escala, apenas um não reúne consenso dos juízes acerca do seu grau de relevância para a avaliação do construto em causa, isto é, apenas um item obteve pontuação inferior a 3 ou 4 pontos na escala Likert. Trata-se do item 32 "Tenho consciência do impacto da reforma no meu estilo de vida?", que foi apontado como necessitando de "uma grande revisão para ser relevante". O IVC obtido para escala como um todo foi de 991 , não tendo nenhum item individualmente obtido a pontuação de 1 "não relevante", por parte de nenhum dos avaliadores. Em relação ao IVC para a clareza dos itens, constata-se que, dos 36 itens da escala, nove não reúnem consenso dos juízes acerca do seu grau de clareza, tendo obtido pontuações na ordem de 1 "nada claro" ou 2 "pouco claro" na escala Likert utilizada. Trata-se dos itens 9, 10, 11, 12,25 , e 26, que obtiveram média de proporção de clareza na ordem dos .833 e dos itens 7, 8 e 32 , que obtiveram média de proporção de clareza na ordem dos .667, sendo estes valores indicativos na necessidade de uma grande revisão. O IVC obtido para escala como um todo foi de .944 .

Tabela 3. Índice de Validade de Conteúdo: percentagem de acordo com juízes relativamente à relevância e clareza dos itens

\begin{tabular}{ccccc} 
Questão & $\begin{array}{c}\text { IVC } \\
\text { Relevância }\end{array}$ & $\begin{array}{c}\text { IVC } \\
\text { Clareza }\end{array}$ & $\begin{array}{c}\text { PA } \\
\text { Relevância }\end{array}$ & $\begin{array}{c}\text { PA } \\
\text { Clareza }\end{array}$ \\
\hline Como me vejo a mim próprio/a, como pessoa, nesta fase de vida? & 1 & 1 & 0,4666667 & 1 \\
Como me vejo a mim próprio/a nesta fase da & 1 & 1 & 1 & 0,466667 \\
$\quad$ vida, em termos de saúde física? & & & & \\
Como me vejo a mim próprio/a nesta fase da & 1 & 1 & 1 & 1 \\
$\quad$ vida, em termos de saúde mental? & 1 & 1 & 1 & 1 \\
$\quad$ Como vejo a histónia da minha vida? & 1 & 1 & 1 & 0,466667 \\
Como me sinto ao pensar no meu passado? & 1 & 1 & 0,6666667 & 0,666667 \\
Como relaciono meu passado com meu futuro? & 1 & 0,667 & 1 & 0,2 \\
Tenho consciência dos meus gostos e interesses? & 1 & 0,667 & 0,4666667 & 0,2 \\
Tenho consciência daquilo que sou capaz de fazer? & 1 & 0,833 & 0,4 & 0,4 \\
Tenho consciência dos meus pontos fortes? & 1 & 0,833 & 0,4666667 & 0,266667 \\
10. Sei o que é importante para mim como pessoa? & 1 & 0,833 & 1 & 0,4 \\
11. Sei o que é importante para mim como membro de uma família? & 1 & 0,833 & 0,666667 & 0,266667 \\
12. Sei o que é importante para mim como cidadão/ã? & 1 & 1 & 0,466667 & 0,466667 \\
13. Que ideias tenho sobre esta fase de vida? & 1 & 1 & 0,4666667 & 0,466667 \\
\hline 14. Que expectativas tenho para esta fase de vida? & & & &
\end{tabular}




\begin{tabular}{|c|c|c|c|c|}
\hline Questão & $\begin{array}{c}\text { IVC } \\
\text { Relevância } \\
\end{array}$ & $\begin{array}{c}\text { IVC } \\
\text { Clareza }\end{array}$ & $\begin{array}{c}\text { PA } \\
\text { Relevância } \\
\end{array}$ & $\begin{array}{c}\text { PA } \\
\text { Clareza }\end{array}$ \\
\hline 15. Que receios tenho sobre esta fase de vida? & 1 & 1 & 0,466667 & 0,466667 \\
\hline 16. Sei que apoios sociais posso ter nesta fase da vida? & 1 & 1 & 0,666667 & 0,666667 \\
\hline 17. Sei que apoios familiares posso ter nesta fase da vida? & 1 & 1 & 1 & 1 \\
\hline 18. Sei como ativar os meus apoios nesta fase da vida? & 1 & 1 & 0,666667 & 0,666667 \\
\hline $\begin{array}{l}\text { 19. Que oportunidades de lazer e/ou voluntariado } \\
\text { já explorei para esta fase da vida? }\end{array}$ & 1 & 1 & 1 & 1 \\
\hline $\begin{array}{l}\text { 20. Que oportunidades de formação e/ou trabalho } \\
\text { já explorei para esta fase da vida? }\end{array}$ & 1 & 1 & 0,466667 & 0,466667 \\
\hline 21. Que oportunidades familiares já explorei para esta fase da vida? & 1 & 1 & 0,466667 & 0,466667 \\
\hline 22. Como me sinto com as outras pessoas? & 1 & 1 & 0,4 & 0,4 \\
\hline 23. Como me relaciono com as outras pessoas? & 1 & 1 & 0,666667 & 0,666667 \\
\hline 24. Gosto de cultivar amizades e procurar novos amigos? & 1 & 1 & 0,666667 & 0,666667 \\
\hline 25. Tenho objetivos para o futuro? & 1 & 0,833 & 0,4 & 0,266667 \\
\hline 26. Tenho planos para o futuro? & 1 & 0,833 & 0,4 & 0,266667 \\
\hline 27. Se não conseguir concretizar os meus planos, que alternativas tenho? & 1 & 1 & 0,666667 & 0,666667 \\
\hline 28. O que estou fazendo para concretizar meus planos para esta fase de vida? & 1 & 1 & 1 & 1 \\
\hline 29. O que estou fazendo para conseguir o que quero nesta fase da vida? & 1 & 1 & 1 & 1 \\
\hline 30. Como reajo diante de obstáculos? & 1 & 1 & 0,466667 & 0,466667 \\
\hline 31. Tenho consciência das mudanças que a reforma traz? & 1 & 1 & 1 & 1 \\
\hline 32. Tenho consciência do impacto da reforma no meu estilo de vida? & 0,667 & 0,667 & 0,466667 & 0,266667 \\
\hline $\begin{array}{l}\text { 33. Tenho consciência do impacto da reforma } \\
\text { na organização do meu dia a dia? }\end{array}$ & 1 & 1 & 1 & 1 \\
\hline 34. Como encaro a reforma? & 1 & 1 & 0,466667 & 0,466667 \\
\hline 35. Como me sinto em relação à reforma? & 1 & 1 & 0,466667 & 0,466667 \\
\hline $\begin{array}{l}\text { 36. Como avalio ou antecipo neste momento meu } \\
\text { grau de satisfação em relação à reforma? }\end{array}$ & 1 & 1 & 1 & 1 \\
\hline Resultados médios: & 0,991 & 0,944 & 24,86667 & 21,6 \\
\hline
\end{tabular}

A partir das análises individuais de cada juiz em relação à relevância e clareza de cada item, calcularam-se ainda dois coeficentes de kappa (k) de Conger, com base na proporção de concordância e na proporção esperada de acordo devido ao acaso. O K $\mathrm{K}_{\text {Conger }}$ para a relevância é de .488 , o que significa concordância "moderada" (Landis, 1977), enquanto o $\mathrm{K}_{\text {Conger }}$ para a clareza é de .379 , o que significa uma "considerável" (Landis \& Koch, 1977). Em ambos os casos, os valores positivos indicam que a concordância observada é maior que a concordância esperada devido ao acaso (Cohen, 1960).

Tabela 4. Índice de Validade de Conteúdo: Kappa de Conger para a relevância e para a clareza da escala

\begin{tabular}{clcccc}
\hline \multicolumn{5}{c}{ Escala Likert (Relevância) } \\
\hline Avaliador & 1 & 2 & 3 & 4 & \\
1 & 0 & 0 & 0,25 & 0,805556 & \\
\hline 2 & 0 & 0 & 0,305556 & 0,6944444 & \\
3 & 0 & 0 & 0,25 & 0,805556 & \\
4 & 0 & 0,027778 & 0,416667 & 0,555556 & \\
5 & 0 & 0,027778 & 0,194444 & 0,666667 & \\
6 & 0 & 0 & 0,166667 & 0,833333 & Soma \\
$\mathrm{Pk}$ & 0 & 0,009259 & 0,236111 & 0,587963 & 0,833333 \\
\hline
\end{tabular}




\begin{tabular}{|c|c|c|c|c|c|}
\hline \multirow[b]{2}{*}{$\mathrm{Pk} 2$} & \multicolumn{5}{|c|}{ Escala Likert (Relevância) } \\
\hline & 0 & $8,57 \mathrm{E}-05$ & 0,055748 & 0,3457 & 0,401535 \\
\hline \multirow[t]{4}{*}{ Sk2 } & 0 & 0,000189 & 0,007909 & 0,022655 & 0,030753 \\
\hline & & & $\mathrm{Pe}=$ & 0,396409 & \\
\hline & & & Kappa & 0,487634 & \\
\hline & \multicolumn{5}{|c|}{ Escala Likert (Clareza) } \\
\hline Avaliador & 1 & 2 & 3 & 4 & \\
\hline 1 & 0 & 0,027778 & 0,222222 & 0,777778 & \\
\hline 2 & 0 & 0 & 0,361111 & 0,638889 & \\
\hline 3 & 0,027778 & 0,194444 & 0,222222 & 0,555556 & \\
\hline 4 & 0 & 0 & 0,388889 & 0,611111 & \\
\hline 5 & 0,027778 & 0,027778 & 0,222222 & 0,722222 & \\
\hline 6 & 0 & 0,027778 & 0,25 & 0,75 & Soma \\
\hline $\mathrm{Pk}$ & 0,009259 & 0,041667 & 0,236111 & 0,550926 & 0,837963 \\
\hline $\mathrm{Pk} 2$ & $8,57 \mathrm{E}-05$ & 0,001736 & 0,055748 & 0,303519 & 0,36109 \\
\hline \multirow[t]{3}{*}{ Sk2 } & 0,000189 & 0,00544 & 0,007909 & 0,018437 & 0,031974 \\
\hline & & & $\mathrm{Pe}=$ & 0,355761 & \\
\hline & & & Kappa= & 0,379113 & \\
\hline
\end{tabular}

\section{Análise do grupo de participantes}

Verificou-se que, em média, os participantes necessitaram de vinte minutos para preencher toda a prova no processo de reflexão falada. De forma geral, os participantes consideraram que as instruções da prova são claras, assim como o esquema de resposta (com quatro alternativas para cada questão). Dois dos participantes sentiram que algumas questões, de certo modo, se repetiam no seu conteúdo, como se "estivessem sempre a perguntar o mesmo" (P1), apesar de também salientarem que as alternativas de resposta fornecidas ajudavam um pouco na sua distinção. Um dos exemplos indicados diz respeito às questões 4 e 5, "Como vejo a história da minha vida?" e "Como me sinto ao pensar no meu passado?"; às questões 25 e 26, "Tenho objetivos para o futuro?" e "Tenho planos para o futuro?"; e às questões 28 e 29 , "O que estou a fazer para concretizar os meus planos para esta fase da vida?" e "O que estou a fazer para conseguir o que quero nesta fase da vida?". Para todas, foi referido que os investigadores estariam "a perguntar duas vezes a mesma coisa, mas de maneira ligeiramente diferente" (P2). Essa situação levou a que alguns dos participantes $(\mathrm{n}=3)$ questionassem se esta seria uma forma de os investigadores confirmarem que eles "estariam a dizer a verdade". Em relação às quatro alternativas de resposta fornecidas para cada questão (em representação dos diferentes estilos de coping), os participantes indicaram se sentir identificados com as várias possibilidades, embora salientassem que talvez fosse difícil encontrar participantes que optassem por responder "não tenho pensado nisso" ou "evito pensar nisso". Um dos participantes mencionou que
As questões que apresentam neste questionário parecem-me tão importantes que duvido que alguém diga que nunca pensou nisto ou que anda a evitar fazê-lo. Por outro lado, acredito que as pessoas que responderiam assim seriam as que não se disporiam, de livre vontade, a responder ao questionário ou a solicitar qualquer tipo de apoio na transição para a reforma. (P4).

\section{Discussão e conclusão}

Este estudo apresenta uma análise da validade de conteúdo de uma nova escala de avaliação dos estilos de coping com as tarefas desenvolvimentais típicas do novo subestádio de desenvolvimento de carreira nos adultos em situação de (transição para a) reforma.

Os resultados obtidos demonstraram que a escala tem qualidades psicométricas teóricas satisfatórias. Por um lado, a escala é de fácil aplicação e compreensão, podendo ser aplicada de forma individual ou coletivamente, num tempo estimado de dez a quinze minutos. Seu formato possibilita também sua informatização, tornando a aplicação e correção rápidas e eficazes. Os participantes representantes da população-alvo do instrumento consideraram que os itens desenvolvidos sob forma de questão e suas respetivas opções de resposta têm, em geral, "validade aparente" (Pasquali, 2011), isto é, são pertinentes mediante o construto medidor e são inteligíveis. Anteciparam, no entanto, que a opção de resposta desenvolvida para representar o estilo de coping passivo poderá encontrar pouca expressão na população. Contudo a literatura na área aponta para a existência de 
diferentes estilos de coping em situação de transição e adaptação para a reforma (Bass, 2011; Denton \& Spencer, 2009; Ekdert, 2010), incluindo um estilo em particular que corresponde às pessoas que, em geral, têm visão negativa dessa fase da vida, associada a sentimentos de negação, confusão, inutilidade e, por isso mesmo, de passividade e até mesmo algum evitamento (De Vries, 1979; Kloep \& Hendry, 2006; Schlossberg, 2003).

Por outro lado, os juízes consideraram, maioritariamente, que os itens/questões apresentadas se constituíam como representações adequadas das várias dimensões e tarefas de desenvolvimento apresentadas. Em relação aos itens que não reuniram consenso, ou seja, em que os juízes não concordaram quanto à dimensão à qual eles se referiam, coloca-se a hipótese de que a forma como a pessoa vê a si própria (por exemplo, em termos de saúde física e mental - itens 2 e 3) e a maneira como se sente em relação à reforma e antecipa o impacto desta no seu dia a dia (por exemplo, itens 32, 33 e 35), tenham sido interpretadas como motivações para explorar, de forma proativa, atividades, recursos e relações para esta nova fase de vida (Bühler, 1964; Havighurst, 1953). É também possível que o foco temporal utilizado nas questões (tempo presente) possa ter dado origem a essa interpretação. No entanto, após análise e discussão pelas suas autoras, considerou-se seguir as recomendações de Almeida e Freire (2003) e Pasquali (2011) de que os referidos itens deveriam ser mantidos dada a existência de um acordo de pelo menos $80 \%$ entre os vários juízes independentes.

Já no que diz respeito às diferentes análises de validade de conteúdo dos itens individualmente e como um todo, no que concerne aos critérios de relevância e de clareza, constatam-se valores bastante elevados, no global. O total do IVC para a relevância foi de .991 , enquanto para a clareza foi de .944 . Contudo alguns autores defendem que, no processo de avaliação dos itens individualmente e tendo em conta o número de juízes $(\mathrm{n}=6)$, a taxa de concordância não deve ser inferior 78 (Polit \& Beck, 2006). E, nesse sentido, em termos de relevância, o item 32 apresentou elevada proporção de desacordo, enquanto, em termos de clareza, os itens 7, 8 e 32 também não geraram consenso entre os juízes. Outro aspecto a salientar prende-se com os valores obtidos para o $\mathrm{K}_{\text {Conger }}$ (de .488 e .379 para relevância e clareza, respectivamente). Esses valores foram inesperadamente baixos quando comparados com a percentagem de acordo global (Pa) em ambos os casos. Esta situação, reconhecida na literatura como o "paradoxo da estatística kappa", ocorre pelo uso das distribuições marginais, com o objetivo de quantificar o valor esperado de concordância devido ao acaso (Pe). Se esse valor foi elevado, o cálculo do Kappa pode converter um elevado valor de concordância (Pa) numa estatística Kappa reduzida (Feinstein \& Cicchetti, 1990).
Nesse sentido, os valores resultantes da estatística Kappa devem ser interpretados com cautela e no conjunto das restantes análises previamente apresentadas e discutidas.

Não obstante os itens 7, 8, 9, 10, 11, 12, 25, 26 e 32 terem obtido, no computo geral, avaliações menos satisfatórias, optou-se pela sua manutenção na escala tendo sido, no entanto, integralmente revistos, em particular no que concerne a sua clareza. Para o efeito, incluíram-se alterações com a finalidade de torná-los mais focados no construto em análise e, portanto, menos generalistas. Apresentam-se como exemplo as alterações efetuadas no item 7, que inicialmente apresentava a seguinte formulação: "Tenho consciência dos meus gostos e interesses?; 4. Sei bem quais são os meus interesses e gosto de explorar coisas novas; 3 . Tenho algumas dúvidas sobre os meus interesses e acho que devia alargar os meus horizontes; 2 . Tenho muitas dúvidas sobre meus interesses, mas acho que já não vale a pena explorar coisas novas; 1. Não tenho pensado nisso"; e que na versão final passou a constar do seguinte: "Tenho consciência dos meus gostos e interesses? 4. Sei bem quais são os meus interesses, e estou sempre aberto/a a conhecer-me melhor; 3. Tenho algumas dúvidas sobre os meus interesses, e acho que posso ter de vir a descobrir mais sobre mim próprio/a em função do que me acontecer; 2 . Tenho muitas dúvidas sobre meus interesses, mas acho que já não vale a pena fazer nada quanto a isso; 1 . Não tenho pensado nisso".

Em suma, a escala demonstrou boa qualidade inicial, motivando o prosseguimento de estudos que possibilitem o aprofundamento de informações psicométricas a seu respeito, nomeadamente em relação às análises empíricas dos itens. Como referido por Beehr e Bowling (2013), apenas o teste empírico dos vários modelos teóricos e das diversas medidas existentes atualmente sobre a reforma permitirá determinar sua relevância, robustez e validade preditiva.

Este trabalho assenta na grande mais valia que um instrumento de avaliação como este pode ter enquanto ferramenta teoricamente sustentada (Hershenson, 2016), que contribui para identificar a situação das pessoas com 55 anos ou mais em fase de transição de carreira, seja em situações de investigação, sobre as implicações psicológicas do processo de reforma (Dentor \& Spencer, 2009), mas principalmente em situações de intervenção, dado que pretende dar pistas de ação aos profissionais de orientação em função das necessidades identificadas nos seus clientes nessa fase específica de vida. O conceito de carreira póscarreira que lhe está subjacente pretende substituir a noção acerca da reforma enquanto uma saída/fim da carreira e introduzir uma nova concetualização enquanto estádio mais tardio de desenvolvimento que reconhece o potencial de crescimento e renovação de carreira das pessoas nesta situação (Wang \& Shi, 2014; Wang \& Shultz, 2010).

\section{(Re)Career Scale - coping styles: content validity}

Abstract: This article presents the study of the validity of the content of the (Re)Career Scale: Coping Styles, consisting of 36 questions about how different people, 55 or older, think and feel about career transitions. The scale was evaluated by recognized 
experts in the field of vocational guidance $(n=6)$ and by a group of participants $(n=4)$ belonging to the target group for which the instrument is intended. The content validity of the scale was assessed through the analysis of the relevance and clarity of the items, as well as the relationship between each item and its dimension. The results obtained indicate satisfactory qualities regarding relevance $(\mathrm{CVI}=.991$; Kappa $=.488)$, the association between item and factor (\%agreement $=95 \%)$ and apparent validity, and improvements were suggested regarding the clarity of some items ( $\mathrm{CVI}=.944$; Kappa $=.379$ ). These results justify the investment in future empirical validation studies namely through factor analyses.

Keywords: coping styles, transition, test validity, careers.

\section{(Re)Career Échelle - styles d'adaptation: validite du contenu}

Résumé: Cet article présente une étude de la validité du contenu de (Re)Career Échelle: Styles d'Adaptation, qui consiste en 36 questions sur la façon dont différentes personnes, âgées de 55 ans ou plus, pensent et ressentent les transitions de carrière. L'échelle a été évaluée par des experts reconnus dans le domaine de l'orientation professionnelle $(n=6)$ et par un groupe de participants $(n=4)$ appartenant au groupe cible auquel l'instrument est destiné. La validité du contenu de l'échelle a été évaluée par l'analyse de la pertinence et de la clarté des items, ainsi que de la relation entre chaque item et sa dimension. Les résultats obtenus indiquent des qualités satisfaisantes concernant la pertinence (IVC =.991; Kappa =.488), I'association entre l'item et le facteur (\% d'accord =95\%) et la validité apparente, et des améliorations ont été suggérées concernant la clarté de certains items (IVC =.944; Kappa =.379). Ces résultats justifient l'investissement dans de futures études de validation empirique, notamment par le biais d'analyses factorielles.

Mots-clés: styles d'adaptation, transition, validité des tests, carrières.

\section{Escala (Re)Career - estilos de afrontamiento: validez del contenido}

Resumen: Este artículo presenta un estudio de la validez del contenido de la Escala (Re)Career: Estilos de Afrontamiento, que consiste en 36 preguntas sobre cómo piensan y sienten las diferentes personas, de 55 años o más, acerca de las transiciones de carrera. La escala fue evaluada por expertos reconocidos en la esfera de la orientación profesional $(n=6)$ y por un grupo de participantes $(n=4)$ pertenecientes al grupo destinatario al que está destinado el instrumento. La validez del contenido de la escala se evaluó mediante el análisis de la pertinencia y la claridad de los elementos, así como la relación entre cada elemento y su dimensión. Los resultados obtenidos indican cualidades satisfactorias en cuanto a la pertinencia (IVC =.991; Kappa $=.488$ ), la asociación entre el ítem y el factor (\% de acuerdo $=95 \%$ ) y la validez aparente, y se sugirieron mejoras en cuanto a la claridad de algunos ítems (IVC =.944; Kappa =.379). Estos resultados justifican la inversión en futuros estudios de validación empírica, a saber, mediante análisis factoriales.

Palabras clave: estilos de afrontamiento, transición, validez de la prueba, carreras.

\section{Referências}

Alexandre, N., \& Coluci, M. (2011). Validade de conteúdo nos processos de construção e adaptação de instrumentos de medidas. Ciência \& Saúde Coletiva, 16, 3061-3068.

Almeida, L. S., \& Freire, T. (2003). Metodologia da investigação em psicologia e educação (3a ed.). Braga: Psiquilibrios.

Arthur, M. B., \& Rousseau, D. M. (Eds.). (2001). The boundaryless career: A new employment principle for a new organizational era. Oxford: University Press on Demand.

Bass, S. (2011). From retirement to "productive aging" and back to work again. In D. C. Carr \& K. Komp (Eds.), Gerontology in the era of the third age: Implications and next steps (pp. 169-188). New York: Springer.

Beehr, T. A., \& Bowling, N. A. (2013). Variations on a retirement theme: Conceptual and operational definitions of retirement. In M. Wang (Ed.), The Oxford handbook of retirement. Oxford: Oxford University Press.

Bühler, C. (1964). The human course of life in its goal aspects. Journal of Humanistic Psychology, 4(1), 1-18.

Cohen, J. (1960). A coefficient of agreement for nominal scales. Educational and Psychological Measurement, 20, 37-46.

Denton, F. T. \& Spencer, B. G. (2009). What is retirement? A review and assessment of alternative concepts and measures. Canadian Journal on Aging, 28, 63-76

De Vries, M. F. K. (1979). Is there life after retirement? California Management Review, 22(1), 69-76.

Ekerdt, D. J. (2010). Frontiers of research on work and retirement. Journal of Gerontology: Social Sciences, 65B, 69-80. 
Erikson, E. H. (1959). Identity and the life cycle: Selected papers. Psychological Issues, 1, 1-171.

Feinstein, A. R., \& Cicchetti, D. V. (1990). High agreement but low kappa: I. The problems of two paradoxes. Journal of clinical epidemiology, 43(6), 543-549.

Greenhaus, J. H., Callanan, G. A., \& Godshalk, V. M. (2010). Career management. Thousand Oaks: Sage.

Hall, D. T. (2004). The protean career: A quarter-century journey. Journal of Vocational Behavior, 65(1), 1-13.

Havighurst, R. J. (1953). Human development and education. Oxford, UK: Longmans.

Hershenson, D. B. (2016). Reconceptualizing retirement: A status-based approach. Journal of Aging Studies, 38, 1-5.

Janeiro, I. N., \& Marques, J. F. (2010). Career coping styles: Differences in career attitudes among secondary school students. International Journal for Educational and Vocational Guidance, 10(1), 35-48.

Kloep, M., \& Hendry, L. B. (2006). Pathways into retirement: Entry or exit? Journal of Occupational and Organizational Psychology, 79(4), 569-593.

Landis, J. R., \& Koch, G. G. (1977). The measurement of observer agreement for categorical data. Biometrics, 33(1), 159-174.

Levinson, D. J. (1978). The seasons of a man's life. New York: Random House.

Levinson, D. J. (1986). A conception of adult development. American Psychologist, 41(1), 3.

Pasquali, L. (2011). Psicometria: Teoria dos testes na Psicologia e na Educação (5a ed.). Petrópolis, RJ: Vozes.

Peck, R. (1956). Psychological developments in the second half of life. In J. E. Anderson (Ed.), Psychological aspects of aging (pp. 42-53). Washington, DC: American Psychological Association.

Pinto, J. C. (2021). Envelhecimento e carreira: Novos contornos. In H. Rebelo-Pinto \& J. C. Pinto, Envelhecimento: Uma abordagem multidisciplinar. Lisboa: Universidade Católica Editora.

Pinto, J. C. \& Rebelo-Pinto, H. (2019). (Re)Career - Let's work on retirement: Apoiando uma transição e adaptação bem-sucedidas para uma carreira pós-carreira. Trabalho apresentado no III Seminário Internacional de
Desenvolvimento de Carreira e Aconselhamento: Novos Contributos da Investigação e Prática, Lisboa, Portugal. Recuperado de http://bit.ly/3iqQ13k

Pinto, J. C., \& Rebelo-Pinto, H. (2020). Escala (Re)Career: Estilos de Coping. Versão para investigação. Lisboa: Faculdade de Ciências Humanas.

Pinto, J. C., Taveira, M. C, \& Ordonez, J. L. (2016). Cómo orientar la gestión de la carrera profesional. Barcelona: Editorial UOC.

Polit, D. F. \& Beck, C. T. (2006). The content validity index: are you sure you know what's being reported? Critique and recommendations. Research in Nursing \& Health, 29, 489-497.

Rubio, D. M., Berg-Weger, M., Tebb, S. S., Lee, S., \& Rauch, S. (2003). Objectifying content validity: Conducting a content validity study in social work research. Social Work Research, 27, 94-105.

Schlossberg, N. K. (2003). Retire smart, retire happy: Finding your true path in life. Washington, DC: American Psychological Association.

Super, D. E. (1953). A theory of vocational development. American Psychologist, 8(5), 185.

Super, D. E. (1980). A life-span, life-space approach to career development. Journal of Vocational Behavior, 16(3), 282-298.

Wang, M., \& Shi, J. (2014). Psychological research on retirement. Annual Review of Psychology, 65, 209-233.

Wang, M., \& Shultz, K. S. (2010). Employee retirement: A review and recommendations for future investigation. Journal of Management, 36,172-206.

Wang, M., \& Wanberg, C. R. (2017). 100 years of applied psychology research on individual careers: From career management to retirement. Journal of Applied Psychology, 102(3), 546.

Wynd, C. A., Schmidt, B., \& Schaefer, M. A. (2003). Two quantitative approaches for estimating content validity. Western Journal of Nursing Research, 25, 508-518.

Recebido:31/03/2020

Revisado: $05 / 11 / 2020$

Aprovado: 19/12/2020 